\title{
Incidence and Clinical Significance of Aberrant T-Cell Marker Expression on Diffuse Large B-Cell Lymphoma Cells
}

\author{
Yuhko Suzukia,b Tsutomu Yoshida ${ }^{c}$ Guoqin Wang ${ }^{\mathrm{e}}$ Takumi Aoki ${ }^{\mathrm{a}}$ \\ Takuji Katayama $^{a}$ Shunsuke Miyamoto $^{d}$ Koji Miyazaki $^{a}$ Keiichi Iwabuchi $^{c}$ \\ Mikio Danbara $^{a}$ Meijin Nakayama $^{d}$ Ryouichi Horie $^{a}$ Hirokazu Nakamine $^{g}$ \\ Yuichi Sato $^{f}$ Naoya Nakamura ${ }^{\text {h }}$ Nozomi Niitsu $^{\text {i }}$ \\ Departments of a Hematology, ${ }^{b}$ Transfusion Medicine and Cell Transplantation, ${ }^{\mathrm{c} P a t h o l o g y}$ and \\ dOtorhinolaryngology, and 'Kitasato Clinical Research Center, Kitasato University School of Medicine, and \\ fDepartment of Molecular Diagnostics, Kitasato University School of Allied Health Sciences, Sagamihara, \\ gDivision of Pathology and Immunology, Kansai University for Medical Science, Osaka, h'Department of Pathology, \\ Tokai University School of Medicine, Isehara, and 'Department of Hematology, Comprehensive Cancer Center, \\ International Medical Center, Saitama Medical University, Hidaka, Japan
}

\section{Key Words}

Aberrant T-cell expression - B-cell lymphoma .

Diffuse large B-cell lymphoma cells · Flow cytometry .

Immunohistochemistry

\begin{abstract}
Introduction: Aberrant expression of T-cell markers is occasionally observed in B-cell lymphomas. We conducted a retrospective study to establish its incidence and to determine its relationship with clinical features of patients with diffuse large B-cell lymphoma (DLBCL). Patients and Methods: We reviewed DLBCL patients diagnosed between January 2002 and April 2009. Patients fulfilled the following criteria: (1) age >18 years, (2) HIV negative, (3) B-cell lymphoma confirmed by restricted expression of surface immunoglobulin light chains by flow cytometry (FCM). Aberrant T-cell marker expression (ATCME) was defined as positivity for CD2, CD3, CD4, CD7, and/or CD8 on DLBCL cells by FCM. Phenotyping was also performed by immunohistochemistry (IHC). Pa-
\end{abstract}

tients were grouped according to positive or negative ATCME and their clinical features including survival were compared. Results: Of 150 patients, 11 (7.3\%) showed ATCME; CD2 and CD7 were most often expressed. ATCME was less often detected and the signal was weaker using IHC. There were no statistically significant differences in clinical features between the two groups. Conclusions: FCM may be useful to detect ATCME in a small amount of lymphoma cells. The mechanism responsible for ATCME, and whether it contributes in any way to the pathogenesis of B-cell neoplastic transformation, requires clarification.

Copyright $\odot 2013$ S. Karger AG, Basel

\section{Introduction}

Diffuse large B-cell lymphoma (DLBCL) is a neoplasm of large B lymphoid cells in which the size of the nucleus equals or exceeds that of a normal macrophage, being more than twice the size of a normal lymphocyte. DLBCL

\section{KARGER}

E-Mail karger@karger.com

www.karger.com/aha
(C) 2013 S. Karger AG, Basel

0001-5792/13/1304-0230\$38.00/0
Yuhko Suzuki, MD, PhD

1-15-1 Kitasato

Minami-ku

Sagamihara, Kanagawa 252-0374 (Japan)

E-Mail ysuzuki-hki@umin.ac.jp 
cells have a diffuse growth pattern, with the disease constituting $25-30 \%$ of adult non-Hodgkin lymphomas (NHL) in Western countries [1] and 33\% in Japan [2].

Aberrant expression of T-cell markers by flow cytometry (FCM) is occasionally found in routine practice. $\mathrm{Ab}$ errant T-cell marker expression (ATCME) has been reported in some B-cell lymphomas [3-7] based on the widespread use of FCM as an auxiliary method employed for the diagnosis of malignant lymphoma. The phenomenon is well known to occur in DLBCL together with chronic inflammation [3] such as in pyothorax-associated lymphoma $[4,5]$, and plasmablastic lymphoma [6, 7], both of which are often associated with Epstein-Barr virus (EBV) infection. It has been shown that EBV latent membrane protein-1 is responsible for the up- and downregulation of a variety of cell surface or cytoplasmic molecules, including Bcl-2 [8-10]. This modulatory effect of EBV infection might conceivably also affect the expression of other T-cell-specific molecules.

In the present study, we examine ATCME in DLBCL by FCM in order to clarify its relationship with clinicopathological features, the potential involvement of EBV infection, and impact on prognosis. Additionally, we compare the results obtained by FCM and immunohistochemistry (IHC).

\section{Patients and Methods}

\section{Patient Selection}

We reviewed DLBCL patients newly diagnosed at the Kitasato University Hospital and satellite hospitals between January 2002 and April 2009 (a period of 88 months). Patients meeting the following inclusion criteria were enrolled in this retrospective cohort study: (1) diagnosis of DLBCL based on pathology and restricted expression or disappearance of immunoglobulin (Ig) light chain by FCM [11], (2) age >18 years, and (3) serologically HIV negative.

The following clinical and pathological factors recorded within 1 month of diagnosis were reviewed and analyzed: age, gender, iatrogenic complications due to immunosuppression, clinical stage, B symptoms, international prognostic index (IPI), expression of CD5 [12], FCM findings including T-cell aberrancy, and laboratory data, including white blood cell count, hemoglobin concentration, platelet count, and serum levels of lactate dehydrogenase, C-reactive protein, calcium, and soluble IL-2 receptor. Clinical response to the $\mathrm{CHOP}$ with or without rituximab was evaluated by CT, which was performed no later than 2 months after the completion of chemotherapy. According to the International Working Criteria [13], patients were characterized either as having a complete response (CR), unconfirmed CR, a partial response, stable disease, or progressive disease. Patients refractory to the first regimen were classified as having progressive disease, even when the scheduled course of the first regimen had not been com- pleted. Relapse was also determined according to the International Working Criteria [13], and the occurrence and time of diseaserelated death was recorded. Survival was defined as the time from the date of diagnosis to the date of death or the end of follow-up. The Ethics Committee of the Kitasato University School of Medicine approved this study.

\section{Pathological Analysis}

Formalin-fixed, paraffin-embedded tissues were stained with hematoxylin-eosin. The histological subtypes were classified according to the criteria of the World Health Organization (4th edition, 2008) [14] by more than two experienced pathologists. IHC was performed using the following primary antibodies (Abs): CD3 (F7.2.38; Dako, Glostrup, Denmark), CD5 (4C7; Novocastra, Newcastle, UK), CD10 (56C6; Novocastra), CD20 (L26; Dako), Bcl-6 (PG-B6p; Dako), and Mum-1 (MUM1p; Dako). Germinal center B-cell and non-germinal center B-cell types were determined according to Hans et al. [15].

DLBCL cells manifesting ATCME by FCM were also tested by IHC using Abs to CD2 (AB75), CD4 (4B12), CD7 (LP15), and CD8 (1A5; all Novocastra). If CD8 was positive by FCM, Abs to TIA-1 (GeneTex, Irvine, Calif., USA) and Granzyme B (11F1; Novocastra) were also used for IHC.

In situ hybridization for EBV-encoded small non-polyadenylated RNAs (EBERs; EBER-ish; DAKO) was also performed according to the manufacturer's instructions.

\section{Flow Cytometry}

We reviewed all enrolled patients' FCM analyses from data consisting of scattergrams and histograms of lymphoma cells, without taking median fluorescence intensities into account. These data were obtained from the SRL Laboratory (Hino, Japan).

Prior to FCM analysis, suspensions of biopsied samples in RPMI medium were stained using combinations of 2 or 3 monoclonal Abs (mAbs) directly conjugated to the fluorescent molecules isothiocyanate and phycoerythrin. Immunophenotypic analysis followed the FCM method reported previously [11]. Analyses were performed within $24 \mathrm{~h}$ after biopsy sampling. To identify the lymphoma cell and to eliminate dead cells, 7-amino-actinomycin $\mathrm{D}$ (7-ADD) staining [16] was performed on samples obtained from January 2007 through the end of the study period. Before using 7-ADD, CD45 gating was used to detect blasts and lymphoma cells $[17,18]$. Thus, CD45 and right angle light scatter were used to gate on blasts and lymphoma cells in three-color analysis.

The routinely used mAbs included CD45 (2D1; Becton Dickinson, BD, Bedford, Mass., USA), CD2 (T11; Beckman-Coulter, BC, Fullerton, Calif., USA), CD3 (CD3, BC), CD4 (T4; BC), CD5 (T1; BC), CD7 (3A1; BC), CD8 (T8; BC), CD10 (J5; BC), CD19 (89B; BC), CD20 (B-Ly1; Dako), CD23 (MHM6; Dako), CD25 (2A3; BD), CD11c (BU15; BC), CD16 (3G8; BC), CD30 (Ber-H2; $\mathrm{BC}), \mathrm{CD} 34$ (581; BC), CD56 (N901; BC), IgM (G20-127; BD), CD38 (T16; BC), $\kappa$-chain (TB 28-2; BD), and $\lambda$-chain (1-155-2; $\mathrm{BD})$.

For the 7-ADD method, mAbs to CD2, CD3, CD4, CD5, CD7, CD8, CD10, CD19, CD20, CD25, CD30, CD34, CD38, CD 45, and $\mathrm{CD} 56$, as well as IgM, $\kappa$-chain and $\lambda$-chain were used. Similar reagent panels were used for CD45 gating as follows: CD2, CD3, CD4, CD5, CD7, CD8, CD10, CD11c, CD16, CD19, CD20, CD23, CD25, CCD30, CD34, CD56, $\kappa$-chain and $\lambda$-chain. 
ATCME was assigned when $>30 \%$ of the lymphoma cells in a sample were positive for $\mathrm{CD} 2, \mathrm{CD} 3, \mathrm{CD} 4, \mathrm{CD} 7$, or CD8. CD5 was not regarded as an aberrant $\mathrm{T}$-cell marker because CD5-positive B-cells, B-1 cells, are normally present and CD5-positive B-cell lymphomas are common $[12,19]$.

\section{Statistics}

Continuous variables are presented as medians (25th and 75th percentiles) and compared using the Mann-Whitney U test. Numerical variables are given as numbers (\%). The relationships between ATCME and clinical and pathological parameters were assessed by Pearson's $\chi^{2}$ test or Fisher's exact test, as appropriate.

Cumulative survival of the patients was estimated using the Kaplan-Meier method, and statistically significant differences between the groups were estimated by log-rank test. For Kaplan-Meier curves, we limited the data to a follow-up period of 60 months to avoid the number at risk being too small. Patients surviving $>60$ months are reported as 60 months, and events occurring after the follow-up period were censored. The 5-year cumulative survival probability was estimated using the life table method with the interval length set at 6 months.

Multivariate analysis was by the Cox proportional hazard regression model to estimate independent prognostic effects of Tcell aberrancy and each of the other clinicopathological parameters on survival, adjusting for confounding factors. Within the present study population, there were 56 DLBCL-related deaths, which allow a maximum of 6 variables to be included in the regression model. The conventional $\mathrm{p}$ value of 0.05 or less was used to determine the level of statistical significance. All reported $p$ values are two sided. Analyses were performed independently at our clinical research center using SPSS version 17.0 software (SPSS, Chicago, Ill., USA).

\section{Results}

\section{Patient Characteristics}

The clinicopathological characteristics of the 150 eligible patients are summarized in table 1. Fifty-eight (38.7\%) were women, aged from 21.0 to 86.0 years (median 67.0 years). There were 28 (18.6\%) stage I, 31 (20.7\%) stage II, 43 (28.7\%) stage III, and $48(32 \%)$ stage IV patients, and a total of 43 patients $(28.7 \%)$ with extranodal involvement. Chemotherapy was given to 121 patients, of whom 29 (19.3\%) received a CHOP or CHOP-like regimen (ChemoTX) and 92 (61.3\%) received rituximab plus $\mathrm{CHOP}$ or a $\mathrm{CHOP}$-like regimen.

Of the 150 DLBCLs, 11 (7.3\%) showed ATCME by FCM. CD2, CD3, CD4, CD7, and CD8 were expressed in $4(2.7 \%), 0(0 \%), 1(0.7 \%), 6(4.0 \%)$, and $2(1.3 \%)$ cases, respectively. Two cases expressed two T-cell antigens. One case with DLBCL having aberrant CD7 expression is shown in figure 1.

\section{Relationships between ATCME and}

\section{Clinicopathological Characteristics}

The clinicopathological features of DLBLC patients stratified according to ATCME were compared. We found no statistically significant difference between clinicopathological features and any ATCME group (table 1).

\section{Relationships between ATCME and Survival}

In the 121 patients receiving ChemoTX with or without rituximab, the response rate (CR, unconfirmed CR and partial response) was $85.6 \%: 85.2 \%$ in the group with T-cell aberrancy and $90.0 \%$ in the remaining patients (nonsignificant).

The overall follow-up period ranged from 0 to 95 months (median, 15.5 months). At the end of the followup, 87 patients were still alive, 35 had relapsed, and 32 had died of their disease (5-year survival probability, 64\%). The mean survival time was 30.8 months. Patients without ATCME had a 5-year survival probability of $64.1 \%$. However, none of the patients with ATCME survived for 60 months (although the difference in overall survival between the two groups was not significant, $\mathrm{p}=0.23$ ).

Cox proportional hazard regression analysis was also performed in the 121 patients to estimate the effect of ATCME on survival. The crude hazard ratio (HR) of the ATCME-positive group relative to the negative group was 0.32 (95\% confidence interval, CI: 0.04-2.32). After controlling for the effects of clinicopathological factors including age, gender, IPI, and having chemotherapy, the adjusted HR of the ATCME-positive group was 0.44 (95\% CI: 0.06-3.32). These findings suggest that $\mathrm{T}$-cell aberrancy had no significant impact on survival (table 2).

\section{Assessment of ATCME by IHC and FCM}

At least two experienced pathologists reviewed the IHC sections. ATCME detected by FCM could be confirmed in some, but not all, of the cases (table 3). EBERish was also performed on the 11 cases with ATCME. Only a single case was found to be positive for EBER. Two DLBCL cases with ATCME are depicted in figure 2.

\section{Discussion}

To the best of our knowledge, this is the first study exploring ATCME in a large series of DLBCL cases. We found that $\mathrm{CD} 2$ and $\mathrm{CD} 7$ expression is relatively common, in agreement with several reports on B-cell NHL (B-NHL), e.g. studies on the expression of CD7 (5\%) and CD2 (2\%) reported by Inaba et al. [20, 21], CD2 and CD8 
Fig. 1. FCM findings of ATCME in a DLBCL case which was confirmed as B-cell lymphoma by Ig light chain restriction. After excluding dead cells by 7-ADD staining, cells from lymph nodes were gated by SSC and FSC. Based on the light chain restriction, $>85 \%$ of the gated cells were $\lambda$-chain positive, suggesting that they were the products of clonally proliferating B cells. They are CD19 and CD7 positive.
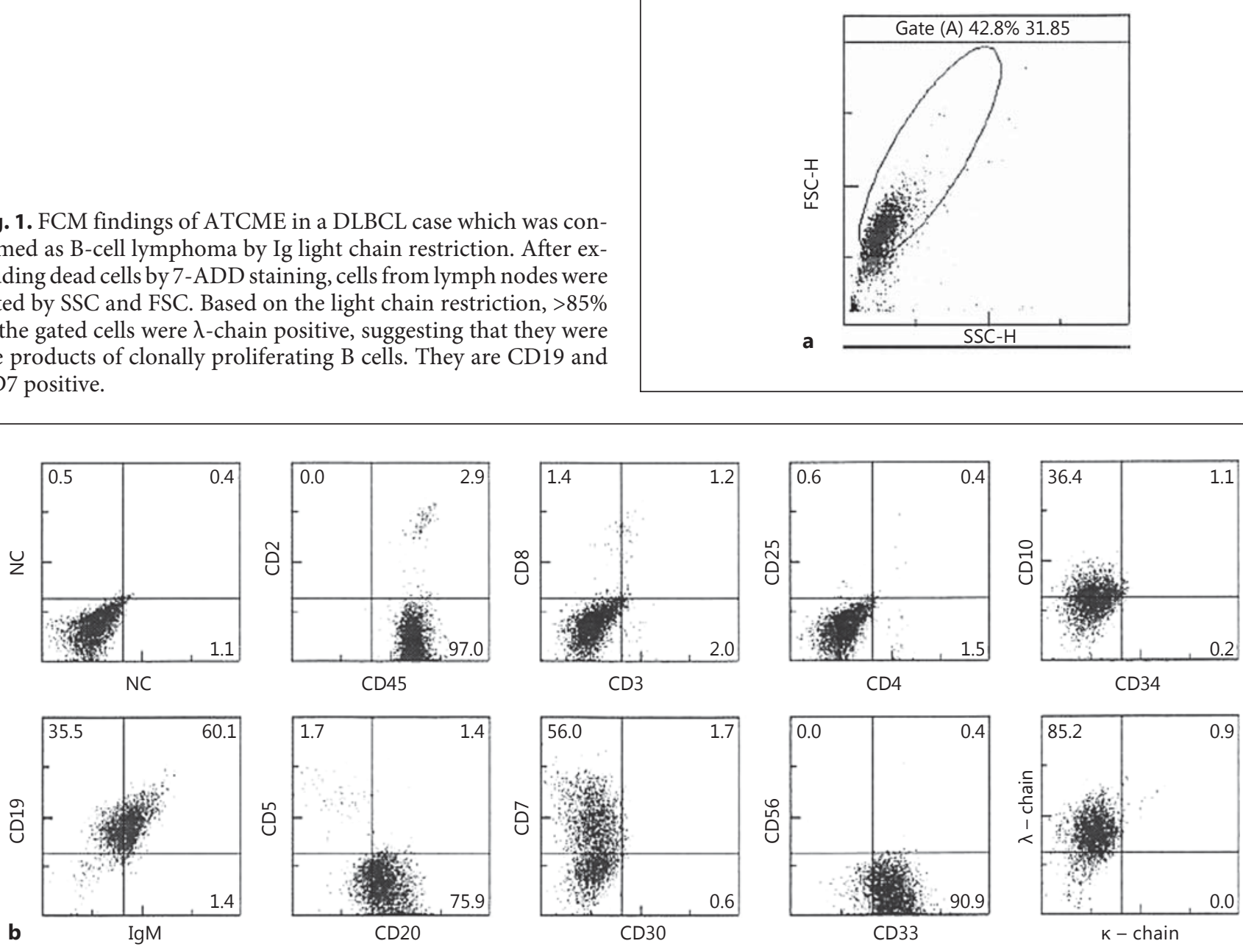

by Kaleem et al. [22], CD2 (38\%) and CD7 (19\%) by Schmidt et al. [23], and CD8 (1.18\%) by Carulli et al. [24].

Regarding CD2 expression, earlier studies found that a small proportion of mature B cells do express CD2 [25, 26 and that this molecule is expressed on a substantial percentage of thymic B cells ( $46 \%$ in the fetal thymus and $75 \%$ in the postnatal thymus). It can also be expressed by mature circulating peripheral blood B cells (CD19+ and $\mathrm{CD} 20+$ ) in normal donors [26]. The presence of CD2 on the cell surface is required to mediate cell adhesion and to facilitate antigen recognition in the absence of intracellular signaling. In the murine model, $\mathrm{CD} 2+\mathrm{B}$ cells are functionally associated with B-cell differentiation. The human and murine $\mathrm{CD} 2$ genes show a high degree of homology in both $5^{\prime}$ and $3^{\prime}$-gene flanking regions, suggesting that they may be regulated in a similar fashion [26].

Aberrant T-Cell Expression and DLBCL
Regarding CD7 expression, it is known that cord blood CD34+, CD7+, CD10-, and CD19- cells can rapidly generate small numbers of CD19+ cells in culture. CD7 expression may characterize an intermediate stage between stem cells, erythroid cells, and pro-B cells in neonates, but may be more closely associated with natural killer lineage-restricted precursors in adult marrow [27]. Thus, normal mature B cells do not express CD7 at all.

Several types of B-cell lymphomas, such as DLBCL with chronic inflammation [3] and plasmablastic lymphoma $[6,7]$, often show ATCME. EBV is considered to contribute to this phenomenon. However, EBER was positive only in a single case in the patients studied here, indicating that EBV is not a major factor responsible for ATCME in our cases. 
Table 1. Characteristics of DLBCL patients $(n=150)$ with T-cell aberrancy

\begin{tabular}{|c|c|c|c|c|}
\hline & \multirow{2}{*}{$\begin{array}{l}\text { Patients } \\
\mathrm{n}\end{array}$} & \multicolumn{2}{|l|}{ T-cell aberrancy } & \multirow[t]{2}{*}{$\mathrm{p}$} \\
\hline & & positive & negative & \\
\hline Age, years & & $67(55.3,74.8)$ & $67(59.0,73.0)$ & 0.96 \\
\hline Gender, male & 92 & $8(72.7)$ & $84(60.4)$ & 0.50 \\
\hline Performance status, $2<$ & 49 & $3(27.2)$ & $46(33.3)$ & 0.59 \\
\hline Extranodal involvement & 43 & $2(18.2)$ & $41(29.5)$ & 0.72 \\
\hline ISC, positive & 30 & $3(27.3)$ & $27(25)$ & 0.54 \\
\hline Stage & & & & 0.62 \\
\hline I & 16 & $2(18.2)$ & $14(10.1)$ & \\
\hline II & 35 & $2(18.2)$ & $33(23.7)$ & \\
\hline III & 30 & $4(36.4)$ & $26(18.7)$ & \\
\hline IV & 69 & $3(27.3)$ & $66(47.5)$ & \\
\hline B symptoms, positive & 52 & $5(45.5)$ & $47(33.8)$ & 0.51 \\
\hline IPI & & & & 0.95 \\
\hline $\mathrm{I}$ & 28 & $2(18.2)$ & $26(20.2)$ & \\
\hline II & 31 & $3(27.3)$ & $28(20.3)$ & \\
\hline III & 43 & $3(27.3)$ & $40(29.0)$ & \\
\hline IV & 48 & $3(27.3)$ & $45(32.6)$ & \\
\hline \multicolumn{5}{|l|}{ FCM findings } \\
\hline CD5 positive & 30 & $1(9.1)$ & $29(20.9)$ & 0.69 \\
\hline CD19 positive & 150 & $11(100)$ & $139(100)$ & 1.00 \\
\hline CD20 negative & 11 & $1(9.1)$ & $10(7.2)$ & 0.38 \\
\hline Hans's criteria & & & & 0.15 \\
\hline Non-GCB & 60 & $7(63.6)$ & $53(38.9)$ & \\
\hline GCB & 57 & $3(27.3)$ & $54(38.9)$ & \\
\hline Laboratory data & 150 & & & \\
\hline $\mathrm{WBC}, \times 10^{9} / 1$ & & $8.0(5.6,9.2)$ & $5.8(4.7,7.9)$ & 0.07 \\
\hline Hemoglobin, g/dl & & $13.0(11.9,14.6)$ & $12.6(11.1,13.7)$ & 0.38 \\
\hline Platelet count, $\times 10^{10} / 1$ & & $24.5(14.1,31.6)$ & $21.2(14.5,27.0)$ & 0.34 \\
\hline LDH, IU/1 & & $244(163,749)$ & $371(226,693)$ & 0.13 \\
\hline C-reactive protein, $\mathrm{g} / \mathrm{l}$ & & $4.9(0.2,44)$ & $13.0(1.1,51.9)$ & 0.26 \\
\hline Calcium, mmol/l & & $2.3(2.1,2.3)$ & $2.3(2.2,2.4)$ & 0.12 \\
\hline Soluble IL-2 receptor, IU/1 & & $1,180(704,4,050)$ & $1,210(708,3,845)$ & 0.97 \\
\hline
\end{tabular}

Continuous variables are presented as medians (25th, 75th percentiles) and compared using the MannWhitney $U$ test. Numerical variables are given as $n(\%)$ and compared with the $\chi^{2}$ test or Fisher's exact test. $\mathrm{GCB}=$ Germinal center B cell; ISC = immunosuppressive condition; LDH = lactate dehydrogenase.

Table 2. Patients with DLBCL treated with CHOP with or without rituximab $(\mathrm{n}=121)$

\begin{tabular}{|c|c|c|c|c|c|c|c|}
\hline & \multirow{2}{*}{$\begin{array}{l}\text { Patients } \\
\mathrm{n}\end{array}$} & \multicolumn{3}{|c|}{ Univariate analysis } & \multicolumn{3}{|c|}{ Multivariate analysis } \\
\hline & & $\mathrm{HR}$ & $95 \% \mathrm{CI}$ & $\mathrm{p}$ & HR & $95 \% \mathrm{CI}$ & $\mathrm{p}$ \\
\hline \multicolumn{8}{|l|}{ Aberrant } \\
\hline Positive & 10 & 0.32 & $0.04-2.32$ & 0.36 & 0.44 & $0.06-3.32$ & 0.43 \\
\hline Age & 121 & 1.00 & $0.97-1.03$ & 0.89 & 0.98 & $0.95-1.01$ & 0.98 \\
\hline \multicolumn{8}{|l|}{ Gender } \\
\hline Female & 42 & 1.03 & $0.51-2.09$ & 0.93 & 1.66 & $0.76-3.62$ & 0.20 \\
\hline IPI & 121 & 11.43 & $2.72-47.96$ & 0.11 & 2.41 & $1.54-3.78$ & $<0.0001$ \\
\hline \multicolumn{8}{|l|}{ CD5 } \\
\hline Positive & 21 & 1.87 & $0.89-3.91$ & 0.10 & 2.04 & $0.88-4.74$ & 0.09 \\
\hline CD20 & 121 & 1.47 & $0.60-3.60$ & 0.13 & 0.71 & $0.50-1.01$ & 0.05 \\
\hline
\end{tabular}



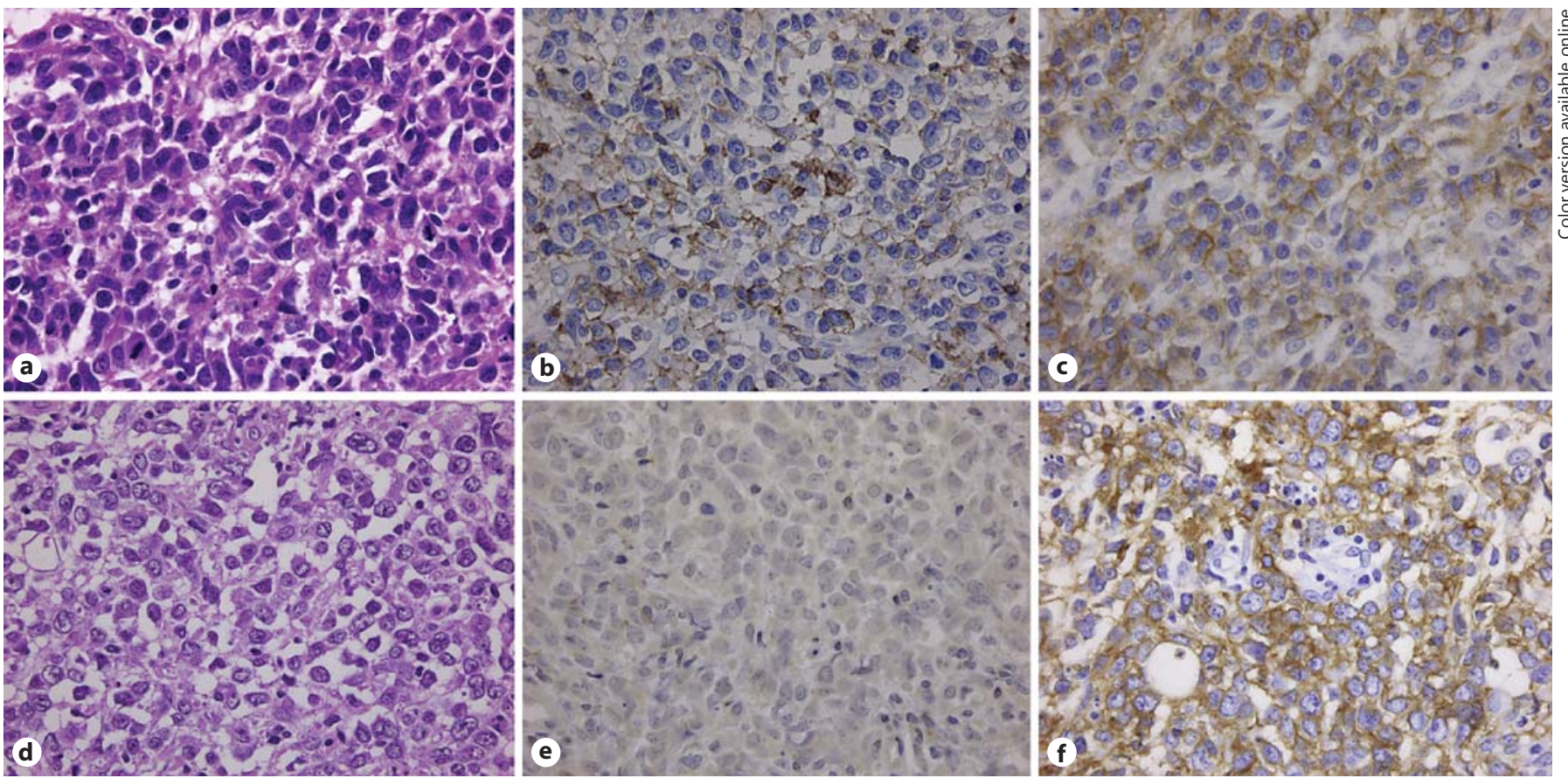

Fig. 2. Histological and IHC images of the biopsied tumors of 2 DLBCL cases. a-c CD7-positive case assessed by FCM. Large cells showing diffuse growth (a) are weakly positive for CD7 (b) and strongly positive for CD20 (c). d-f CD2 positivity by FCM. Large cells showing diffuse growth (d) are negative for CD2 (e) and strongly positive for CD20 (f). a, d HE, original magnification $\times 40$ (objective). b, c, e, f Immunoperoxidase staining with hematoxylin counterstain, original magnification, $\times 40$ (objective).
Table 3. Association between FCM and IHC findings of T-cellrelated molecules expressed in DLBCL

\begin{tabular}{lll}
\hline & FCM positive & IHC positive \\
\hline CD2 & 3 & 1 \\
CD3 & 0 & 0 \\
CD4 & 1 & 0 \\
CD7 & 7 & 3 \\
CD8 & 2 & 1 \\
TIA-1 & & 0 \\
Granzyme B & & 0 \\
\hline
\end{tabular}

The reasons for ATCME are unclear, especially for the cases which have no normal counterparts, like CD3, CD4, CD7 or CD8 B-lymphocyte positivity. There may be technical difficulties in the detection of at least some of these antigens. FCM findings in the present study were only occasionally confirmed by IHC. This is probably due to relatively low numbers of T-cell-related markers expressed on the surface of neoplastic B cells that can be visualized by the more sensitive FCM technique. Normal
T cells were always stained in the IHC sections examined, demonstrating that detection of T-cell surface markers is not generally problematic.

The assessment of ATCME in B-NHL may be useful to monitor the neoplastic component for detecting minimum residual disease, small populations with bone marrow involvement, CNS involvement, and earlier relapse. FCM analyses are not always performed in daily medical practice. Therefore, we stress that monitoring ATCME in patients with B-NHL can be reliably performed only by FCM but not IHC.

In our study, ATCME did not appear to be related to any clinicopathological features or survival. In the literature, $\mathrm{CD} 2$ or $\mathrm{CD} 7$ expression is reported to be associated with extranodal involvement in B-NHL at diagnosis [20]. Carulli et al. [24] estimated the frequency of CD8-positive B-NHL to be $1.89 \%$, similar to our finding (1.7\%). They suggested that such B-NHLs are characterized by a more favorable outcome. Other studies have also indicated that CD8 co-expression is a marker for less aggressive disease in chronic lymphocytic leukemia/small lymphocytic lymphoma, but also an indicator of aggressive clinical behavior and involvement of the central nervous system in 
mantle-cell lymphoma $[28,29]$. However, since the results of our analysis are based on limited patient numbers, further studies are required to determine the bona fide clinicopathological significance of CD8 expression in BNHL. To the best of our knowledge, there are no other reports on the clinicopathological significance of ATCME in DLBCL in the literature to date.

In conclusion, we have documented ATCME in a small proportion of DLBCL patients and shown that EBV does not appear to be primarily involved in this phenomenon. ATCME had no statistically significant impact on the survival of these DLBCL patients. To monitor ATCME in these patients, it is important to employ FCM because the ability of IHC to detect ATCME was very poor. It is hoped that we will be able to elucidate the mechanism(s) involved in ATCME in DLBCL, which could contribute to developing the most suitable treatment modality. The accumulation of a larger set of clinicopathological and survival data in this rare type of lymphoma could reveal significant differences in the disease course, and treatment requirements only hinted at the trend towards poorer survival in the small cohort of 11 patients examined here.

\section{Acknowledgments}

We would like to thank our colleagues, especially D.V.M. Taira, Ms. Yamanaka in the Hematology Department, and Ms. Tsuruta in the Pathology Department. Additionally, we also thank Mr. Horigome at SRL for his detailed information on mAbs used in FCM.

\section{References}

1 Stein H, Chan JKC, Warnke RA, Gatter KC, Chan WC, Campo E, Jaffe ES: Diffuse large B-cell lymphoma, not otherwise specified; in Swerdlow SH, Campo E, Harris NL, Jaffe ES, Pileri SA, Stein H, Thiele J, Vardiman JW (eds): WHO Classification of Tumours of Haematopoietic and Lymphoid Tissues. Geneva, WHO, 2008, pp 233-237.

2 Aoki R, Karube K, Sugita Y, Nomura Y, Shimizu K, Kimura Y, Hashikawa K, Suefuji N, Kikuchi M, Ohshima K: Distribution of malignant lymphoma in Japan: analysis of 2260 cases, 2001-2006. Pathol Int 2008;58:174182.

3 Chan JKC, Aozasa K, Gaulard P: DLBCL associated with chronic inflammation; in Swerdlow SH, Campo E, Harris NL, Jaffe ES, Pileri SA, Stein H, Thiele J, Vardiman JW (eds): WHO Classification of Tumours of Haematopoietic and Lymphoid Tissues. Geneva, WHO, 2008, pp 245-246.

4 Mori N, Yatabe Y, Narita M, Kobayashi T, Asai J: Pyothorax-associated lymphoma. An unusual case with biphenotypic character of $\mathrm{T}$ and B cells. Am J Surg Pathol 1996;20:760766.

5 Petitjean B, Jardin F, Joly B, Martin-Garcia N, Tilly H, Picquenot JM, Briere J, Danel C, Mehaut S, Abd-Al-Samad I, Copie-Bergman C, Delfau-Larue MH, Gaulard P: Pyothorax-associated lymphoma: a peculiar clinicopathologic entity derived from B cells at late stage of differentiation and with occasional aberrant dual B- and T-cell phenotype. Am J Surg Pathol 2002;26:724-732.
6 Stein H, Harris NL, Campo E: Plasmablastic lymphoma; in Swerdlow SH, Campo E, Harris NL, Jaffe ES, Pileri SA, Stein H, Thiele J, Vardiman JW (eds): WHO classification of tumours of haematopoietic and lymphoid tissues. Geneva, WHO, 2008, pp 256-257.

7 Suzuki Y, Yoshida T, Nakamura N, Kamata H, Kotani S, Ohsaka M, Kajita S, Miyazaki K, Ohtani S, Nakayama M, Horie R, Hayakawa K, Niitsu N, Higashihara M: CD3and CD4-positive plasmablastic lymphoma: a literature review of Japanese plasmablastic lymphoma cases. Intern Med 2010;49:18011805

-8 Gregory CD, Dive C, Henderson S, Smith CA, Williams GT, Gordon J, Rickinson AB: Activation of Epstein-Barr virus latent genes protects human B cells from death by apoptosis. Nature 1991;349:612-614.

$\checkmark 9$ Henderson S, Rowe M, Gregory C, CroomCarter D, Wang F, Longnecker R, Kieff E, Rickinson A: Induction of bcl-2 expression by Epstein-Barr virus latent membrane protein 1 protects infected B cells from programmed cell death. Cell 1991;65:1107-1115.

10 Rowe M, Peng-Pilon M, Huen DS, Hardy R, Croom-Carter D, Lundgren E, Rickinson AB: Upregulation of bcl-2 by the Epstein-Barr virus latent membrane protein LMP1: a B-cellspecific response that is delayed relative to NF-kappa B activation and to induction of cell surface markers. J Virol 1994;68:56025612 .

11 Geary WA, Frierson HF, Innes DJ, Normansell DE: Quantitative criteria for clonality in the diagnosis of B-cell non-Hodgkin's lymphoma by flow cytometry. Mod Pathol 1993; 6:155-161.
12 Yamaguchi M, Nakamura N, Suzuki R, Kagami Y, Okamoto M, Ichinohasama R, Yoshino T, Suzumiya J, Murase T, Miura I, Ohshima K, Nishikori M, Tamaru J, Taniwaki M, Hirano M, Morishima Y, Ueda R, Shiku H, Nakamura S: De novo CD5+ diffuse large Bcell lymphoma: results of a detailed clinicopathological review in 120 patients. Haematologica 2008;93:1195-1202.

13 Cheson BD, Horning SJ, Coiffier B, Shipp MA, Fisher RI, Connors JM, Lister TA, Vose J, Grillo-Lopez A, Hagenbeek A, Cabanillas F, Klippensten D, Hiddemann W, Castellino R, Harris NL, Armitage JO, Carter W, Hoppe R, Canellos GP: Report of an international workshop to standardize response criteria for non-Hodgkin's lymphomas. NCI Sponsored International Working Group. J Clin Oncol 1999; 17:1244.

14 Swerdlow SH, Campo E, Harris NL, Jaffe ES, Pileri SA, Stein H, Thiele J, Vardiman JW (eds): WHO Classification of Tumours of Haematopoietic and Lymhoid Tissues. Lyon, International Agency for Research on Cancer, 2008.

15 Hans CP, Weisenburger DD, Greiner TC, Gascoyne RD, Delabie J, Ott G, Muller-Hermelink HK, Campo E, Braziel RM, Jaffe ES, Pan Z, Farinha P, Smith LM, Falini B, Banham AH, Rosenwald A, Staudt LM, Connors JM, Armitage JO, Chan WC: Confirmation of the molecular classification of diffuse large B-cell lymphoma by immunohistochemistry using a tissue microarray. Blood 2004;103:275-282.

16 Shenkin M, Babu R, Maiese R: Accurate assessment of cell count and viability with a flow cytometer. Cytometry B Clin Cytom 2007;72: 427-432. 
17 Borowitz MJ, Guenther KL, Shults KE, Stelzer GT: Immunophenotyping of acute leukemia by flow cytometric analysis. Use of CD45 and right-angle light scatter to gate on leukemic blasts in three-color analysis. Am J Clin Pathol 1993;100:534-540.

18 Hassett J, Parker J: Laboratory practices in reporting flow cytometry phenotyping results for leukemia/lymphoma specimens: results of a survey. Cytometry 1995;22:264-281, discussion 330 .

19 Yamaguchi M, Seto M, Okamoto M, Ichinohasama R, Nakamura N, Yoshino T, Suzumiya J, Murase T, Miura I, Akasaka T, Tamaru J, Suzuki R, Kagami Y, Hirano M, Morishima Y, Ueda R, Shiku H, Nakamura S: De novo CD5+ diffuse large B-cell lymphoma: a clinicopathologic study of 109 patients. Blood 2002;99:815-821.

20 Inaba T, Shimazaki C, Sumikuma T, Okano A, Hatsuse M, Okamoto A, Takahashi R, Ashihara E, Hibi S, Sudo Y, Yamagata N, Murakami S, Rin K, Fujita N, Yoshimura M, Nakagawa M: Expression of T-cell-associated antigens in B-cell non-Hodgkin's lymphoma. Br J Haematol 2000;109:592-599.
21 Inaba T, Shimazaki C, Sumikuma T, Nakagawa $\mathrm{M}$ : T-cell associated antigen-positive Bcell lymphoma. Leuk Lymphoma 2001;42: 1161-1171.

22 Kaleem Z, White G, Zutter MM: Aberrant expression of T-cell-associated antigens on Bcell non-Hodgkin lymphomas. Am J Clin Pathol 2001;115:396-403.

23 Schmidt CJ, Domenico L, Ward P, Barcos MP, Stewart CC: Aberrant antigen expression detected by multiparameter three color flow cytometry in intermediate and high grade Bcell lymphomas. Leuk Lymphoma 1999;34: 539-544.

24 Carulli G, Stacchini A, Marini A, Ciriello MM, Zucca A, Cannizzo E, Aliberti S, Demurtas A, Novero D, Calcagno L, Callegari T, Petrini M: Aberrant expression of CD8 in B-cell non-Hodgkin lymphoma: a multicenter study of 951 bone marrow samples with lymphomatous infiltration. Am J Clin Pathol 2009;132: 186-190, quiz 306.
25 Sen J, Rosenberg N, Burakoff SJ: Expression and ontogeny of CD2 on murine B cells. J Immunol 1990;144:2925-2930.

26 Kingma DW, Imus P, Xie XY, Jasper G, Sorbara L, Stewart C, Stetler-Stevenson M: CD2 is expressed by a subpopulation of normal $\mathrm{B}$ cells and is frequently present in mature B-cell neoplasms. Cytometry 2002;50:243-248.

27 Rossi MI, Yokota T, Medina KL, Garrett KP, Comp PC, Schipul AH Jr, Kincade PW: B lymphopoiesis is active throughout human life, but there are developmental age-related changes. Blood 2003;101:576-584.

28 Schroers R, Hildebrandt Y, Steffens R, Becker S, Ohms G, von Bonin F, Haase D, Bertsch HP, Trumper L, Griesinger F: Immunophenotypic and genetic characterization of a CD8 positive mantle cell lymphoma in a patient with concomitant Mycosis fungoides. Eur J Haematol 2005;75:78-84.

29 Hoffman DG, Tucker SJ, Emmanoulides C, Rosen PA, Naeim F: CD8-positive mantle cell lymphoma: a report of two cases. Am J Clin Pathol 1998;109:689-694. 